\title{
EL CONSEJO DE ESTADO COLOMBIANO COMO JUEZ DE CONVENCIONALIDAD
}

\section{COLOMBIAN COUNCIL OF STATE AS CONVENTIONALITY JUDGE}

\author{
Margarita Cárdenas Poveda ${ }^{1}$ \\ INGRID SUÁREZ OSMA ${ }^{2}$
}

\begin{abstract}
RESUMEN: En este trabajo se exponen los criterios que utiliza el Consejo de Estado colombiano para efectuar el control de convencionalidad en sus sentencias y se analiza la jurisprudencia en la que ha utilizado dicho control como herramienta para solucionar diversos casos. En consecuencia, se ha prestado especial atención a las razones dadas por esta alta corporación, para justificar su rol como juez de convencionalidad, a la luz de la Convención Americana de Derechos Humanos y de la Jurisprudencia de la Corte Interamericana de Derechos Humanos.
\end{abstract}

Palabras clave: Control de convencionalidad, Corte Interamericana de Derechos Humanos, Consejo de Estado, Colombia.

ABSTRACT: This work exposes the criteria that the Colombian Council of State uses to apply the conventionality control on its judgements. This research analyses the cases where the Council of State have applied the conventionality control as a mean to resolve disputes under its jurisdiction. To that end, special attention has been paid to the reasons given by this judicial corporation, to justify its role as a conventionality judge, that in light of the American Convention on Human Rights and the Inter-American Court of Human Rights.

Keywords: Control of conventionality, Inter-American Court of Human Rights, Council of State, Colombia.

\section{INTRODUCCIÓN}

Desde el año 2006, la Corte Interamericana de Derechos Humanos (en adelante Corte IDH o Corte Interamericana) ha venido desarrollando en su jurisprudencia la doctrina del control de convencionalidad, en virtud de la cual los Estados bajo su jurisdicción

\footnotetext{
1 Doctora en Sociología Jurídica de la Universidad Externado de Colombia. Profesora de planta de la Universidad de La Sabana. Código Orcid 0000-0001-9922-6429. Miembro del Grupo de Investigación Justicia, Ámbito Público y Derechos Humanos, categorizado en A por Colciencias, Línea de investigación en razonamiento jurídico de la Facultad de Derecho y Ciencias Políticas de la Universidad de La Sabana. Dirección postal: U. de La Sabana, Campus del Puente del Común, Km. 7, Autopista Norte de Bogotá, Chía, Cundinamarca, Colombia. Dirección electrónica: margarita.cardenas@unisabana.edu.co.

2 Magister en Derecho Constitucional de la Universidad de La Sabana. Miembro del Grupo de Investigación Justicia, Ámbito Público y Derechos Humanos, categorizado en A por Colciencias, línea de investigación en razonamiento jurídico de la Facultad de Derecho y Ciencias Políticas de la Universidad de La Sabana. Código Orcid 0000-0002-0804-357X. Dirección postal: U. de La Sabana, Campus del Puente del Común, Km. 7, Autopista Norte de Bogotá, Chía, Cundinamarca, Colombia. Dirección electrónica: ingridso@unisabana.edu.co. Este artículo corresponde al resultado de una investigación del Proyecto denominado "Hacia la unificación del concepto de la responsabilidad civil y del Estado", perteneciente al Grupo de investigación Justicia, Ámbito Público y Derechos Humanos de la Facultad de Derecho y Ciencias Políticas de la Universidad de La Sabana.
} 
deben efectuar un control de convencionalidad interno, a fin de garantizar el efecto útil de la Convención Americana sobre Derechos Humanos (en adelante CADH o Convención Americana) y por tanto la efectiva protección de los derechos y libertades reconocidos en este instrumento.

La doctrina del control de convencionalidad interno o difuso, como también se le conoce, ha generado discusiones interesantes motivadas por diversas preocupaciones. Por ejemplo, pese a los esfuerzos argumentativos de la Corte IDH y del respaldo de un amplio sector de la doctrina ${ }^{3}$, aún persiste el cuestionamiento sobre el fundamento normativo del deber estatal de hacer un control de convencionalidad que implique ajustar el ordenamiento jurídico interno a la jurisprudencia de la Corte Interamericana ${ }^{4}$.

Tal y como se mencionó, el control de convencionalidad interno aparece como un deber estatal, no obstante, resulta legítimo preguntarse qué autoridades estatales son las obligadas a realizar este control. Pese a que, a lo largo de su jurisprudencia, la Corte IDH no ha sido plenamente constante y consistente a la hora de identificar las autoridades nacionales que deben efectuar el control de convencionalidad, desde su sentencia en el caso Almonacid Arellano en el 2006, la Corte Interamericana ha dejado ver que considera que las autoridades judiciales están llamadas a desarrollar un papel primordial en la efectividad del control de convencionalidad y, en general, en la garantía de los derechos humanos. No obstante, la más reciente jurisprudencia interamericana ha dejado en claro que todas las autoridades estatales están llamadas a realizar el control de convencionalidad interno5.

En todo caso, desde el tribunal regional no se ha impuesto una forma específica de organización que deban adoptar los Estados para cumplir con el deber de realizar el control de convencionalidad interno ${ }^{6}$. Por el contrario, cada Estado debe buscar la mejor forma de organización para que sus autoridades, dentro de sus respectivas competencias, efectúen este control. En consecuencia, resulta altamente enriquecedor el estudio de autoridades públicas concretas de diferentes Estados, con el ánimo de ver las diferentes maneras en que las autoridades estatales están asumiendo, recibiendo o rechazando la doctrina del control de convencionalidad.

Es por ello que no se ha tenido una respuesta uniforme en los Estados del Sistema Interamericano de Derechos Humanos (en adelante SIDH) e incluso, dentro de cada Estado las autoridades públicas no necesariamente han asumido una misma actitud. Este ha sido el caso de Colombia, en el que la Corte Constitucional se ha mostrado reticente a adoptar de forma amplia e irrestricta la doctrina del control de convencionalidad en los términos en los que la Corte interamericana la entiende ${ }^{7}$. Esta actitud contrasta con la del

\footnotetext{
3 Sagüés (2010), García Ramírez (2011) pp. 123-159, Ferrer Mac-Gregor (2011) pp. 531-532.

4 Vítolo (2013) pp. 357-380, Malarino (2010) pp. 425-446.

5 Gelman vs. URUGUay (2011); MAsacres de Río Negro vs. Guatemala (2012); Masacre de SANTo Domingo vs. COLOMBIA (2012) y ROCHAC HERNÁNDEZ Y OTROS VS. EL SALVADOR (2014).

6 Liakat Ali Alibux vs. Suriname (2014). Una reflexión al respecto puede verse en García Ramírez (2011) pp. 133-138.

7 Por ejemplo, en la Sentencia C-442 de 2011, M.P.: Humberto Antonio Sierra Porto, los ciudadanos, en ejercicio de una acción pública de inconstitucionalidad, le pidieron a la Corte Constitucional, declarar contrario a la Constitución las normas del Código Penal que tipifican los delitos de injuria y calumnia, con fundamento en
} 
Consejo de Estado colombiano que, como tribunal de cierre de la jurisdicción de lo contencioso administrativo, se ha apropiado de la jurisprudencia interamericana y ha adoptado un rol activo en la aplicación del control de convencionalidad interno.

En este contexto, resulta de especial relevancia detenerse a analizar la manera en que las autoridades estatales se están aproximando al control de convencionalidad. Con este trabajo se busca analizar detenidamente la forma en que el Consejo de Estado colombiano se ha aproximado a este nuevo deber y cómo lo ha aplicado en al ámbito práctico. En esta investigación, se analiza la jurisprudencia del Consejo de Estado en la que se ha utilizado el control de convencionalidad como herramienta para solucionar los casos que se le presentan. Para tal fin, se ha prestado especial atención a las razones dadas por el Consejo de Estado para justificar su rol como juez de convencionalidad.

Por lo expuesto, el problema objeto de investigación de manera concreta consistió en identificar cuáles son los argumentos del Consejo de Estado colombiano para justificar la aplicación del control de convencionalidad interno. El tipo de investigación utilizado es el descriptivo y analítico, de la jurisprudencia del Consejo de Estado en la que ha aplicado el control de convencionalidad y el método corresponde al análisis -síntesis de fuentes documentales, jurisprudenciales primordialmente, que han permitido determinar con claridad la aplicación del control de convencionalidad en las sentencias del Consejo de Estado colombiano.

\section{LA DOCTRINA DEL CONTROL DE CONVENCIONALIDAD INTERNO}

Dado que, como se explicó, el objetivo principal de este trabajo es identificar los argumentos esgrimidos por el Consejo de Estado colombiano para justificar su rol como juez de convencionalidad, así como los criterios utilizados en la aplicación del control de convencionalidad en sus decisiones, principalmente de casos en los que se demanda la responsabilidad del Estado colombiano, resulta pertinente hacer algunas precisiones generales sobre el control de convencionalidad interno en el SIDH.

Debe empezarse por decir que, aunque no siempre se le haya conocido bajo ese nombre, el control de convencionalidad no es una figura nueva en el Derecho Internacional pues su existencia va de la mano con la ratificación de tratados cuya guarda se le confiere a un órgano jurisdiccional regional o internacional, quien se encarga de confrontar las conductas estatales con las obligaciones contenidas en el instrumento internacional previamente ratificado ${ }^{8}$.

Para el caso del Sistema Interamericano, se trata de una competencia inherente a la Corte Interamericana para la protección internacional de la persona9 ${ }^{9}$ De allí que este control tenga una longeva existencia en el SIDH evidenciado en los múltiples casos en los que la Corte IDH ha declarado que la normativa nacional es contraria a la $\mathrm{CADH}$, llegado incluso a considerarse que "la responsabilidad internacional del Estado puede generarse por

la jurisprudencia interamericana sobre la libertad de expresión. Concretamente, aquella oportunidad, los ciudadanos pidieron a la Corte que realizara un control de convencionalidad, petición que no fue atendida favorablemente por el tribunal constitucional.

8 Londoño Lázaro (2010) pp. 796-798.

9 Cfr. Salado Osuna (2008) p. 101, citado por Rey Cantor, (2008) p. 43. 
actos u omisiones de cualquier poder u órgano de éste, independientemente de su jerarquía, que violen la Convención Americana"10, incluyendo normas constitucionales ${ }^{11}$.

Hay consenso en la doctrina en afirmar que en el SIDH el término control de convencionalidad fue usado por primera vez por parte del juez Sergio García Ramírez en el 2003 en su voto concurrente razonado del caso Myrna Marck Chang vs. Guatemala ${ }^{12}$, quien en esa oportunidad lo utilizó para referirse al control de la adecuación del ordenamiento interno de los Estados con la Convención Americana, objeto propio de la tarea del tribunal regional. Posteriormente, esta tesis fue reiterada por el mismo juez en su voto razonado del caso Vargas Areco vs. Paraguay ${ }^{13}$.

Dentro del SIDH el control de convencionalidad aparece como una herramienta para asegurar la supremacía de la $\mathrm{CADH}^{14}$, incluso por encima de las constituciones nacionales $^{15}$, en tanto que constituye un examen en el que las conductas estatales son confrontadas con la Convención Americana incluyendo las interpretaciones que la Corte IDH ha hecho de la $\mathrm{CADH}$. Se presenta entonces como un instrumento eficaz para el respeto,

10 Olmedo Bustos vs. ChILE (2001). En este caso la inconvencionalidad que llevó a la declaratoria de responsabilidad de Chile, se produjo a causa de "el artículo 19 número 12 de la Constitución establece la censura previa en la producción cinematográfica y, por lo tanto, determina los actos de los Poderes Ejecutivo, Legislativo y Judicial”.

11 En el caso BoYCE VS. BARBADOs (2007), de manera expresa se le ordenó al Estado tomar las medidas para eliminar los efectos de la "cláusula de exclusión constitucional". En el numeral 8 de la parte resolutiva de la sentencia, la Corte IDH dispuso: "El Estado debe adoptar, dentro de un plazo razonable, contado a partir de la fecha de notificación de la presente Sentencia, aquellas medidas legislativas o de otra índole que sean necesarias para asegurar que la Constitución y la legislación de Barbados cumplan con la Convención Americana y, en especial, eliminar el efecto del artículo 26 de la Constitución de Barbados con respecto a la inimpugnabilidad de las "leyes existentes", en los términos de los párrafos 127(c) a 128 de este Fallo".

12 Expresamente el juez afirmó: "Para los efectos de la Convención Americana y del ejercicio de la jurisdicción contenciosa de la Corte Interamericana, el Estado viene a cuentas en forma integral, como un todo. En este orden, la responsabilidad es global, atañe al Estado en su conjunto y no puede quedar sujeta a la división de atribuciones que señale el Derecho interno. No es posible seccionar internacionalmente al Estado, obligar ante la Corte solo a uno o algunos de sus órganos, entregar a éstos la representación del Estado en el juicio -sin que esa representación repercuta sobre el Estado en su conjunto- y sustraer a otros de este régimen convencional de responsabilidad, dejando sus actuaciones fuera del "control de convencionalidad" que trae consigo la jurisdicción de la Corte internacional". García Ramírez (2003) voto razonado concurrente, a la sentencia del caso Mack Chang vs. Guatemala (2003).

13 García Ramírez (2006), Voto razonado a propósito de la sentencia caso VARGAS ARECO VS. PARAGUAY (2006) Textualmente el juez afirmó: "La Corte Interamericana, que tiene a su cargo el 'control de convencionalidad' fundado en la confrontación entre el hecho realizado y las normas de la Convención Americana, no puede, ni pretende -jamás lo ha hecho-, convertirse en una nueva y última instancia para conocer la controversia suscitada en el orden interno. La expresión de que el Tribunal interamericano constituye una tercera o cuarta instancia, y en todo caso una última instancia, obedece a una percepción popular, cuyos motivos son comprensibles, pero no corresponde a la competencia del Tribunal, a la relación jurídica controvertida en este, a los sujetos del proceso respectivo y a las características del juicio internacional sobre derechos humanos". BAZÁN (2012) también refiere que el Juez García Ramírez (2006), en su intervención como Presidente de la Corte IDH en la ceremonia de apertura del Período Extraordinario de Sesiones del Tribunal en Brasilia, quien indicó que la Corte Interamericana es una "corte de convencionalidad, semejante a las de constitucionalidad en los ordenamientos nacionales".

14 Thury Cornejo (2012).

15 SAgỨés (2010) p. 1247. 
la garantía y ejercicio efectivo de los derechos descritos por la $\mathrm{CADH}^{16}$, cuya garantía es competencia última de la Corte IDH pero supone una actuación previa por parte de los Estados dentro de sus jurisdicciones.

A pesar de no existir una disposición convencional que expresamente obligue a los Estados a realizar un control de convencionalidad interno, y mucho menos con las características y alcance que le ha venido dando la Corte IDH, este Tribunal ha hecho un esfuerzo para defender este deber desde el texto de la Convención Americana ${ }^{17}$. La defensa que hace la Corte Interamericana podría sintetizarse en el principio del efecto útil de la $\mathrm{CADH}^{18}$ y el pacta sunt servanda, sumado a los deberes de respeto y garantía contenidos en los artículos 1.1 y 2 de la Convención, para cuyo cumplimiento el control de convencionalidad se presenta como una herramienta efectiva ${ }^{19}$.

Ahora bien, más allá de las críticas y defensas que pueda recibir el control de convencionalidad en lo referente a su justificación y legitimidad, es relevante señalar que en el SIDH se han configurado dos clases de control de convencionalidad que ha recibido diferentes denominaciones por la doctrina, de un lado tenemos el control de convencionalidad externo o en sede internacional -también llamado concentrado- y por otra parte el control de convencionalidad interno o en sede nacional -también llamado difuso-.

El primer tipo, el que se realiza en sede internacional, corresponde al concepto tradicional u original ${ }^{20}$ de control de convencionalidad al que se hizo referencia atrás, en él la Corte Interamericana tiene el papel protagónico pues es quien lo realiza en razón a sus propias competencias y finalidad. Pero, a partir de la jurisprudencia de este Tribunal, la doctrina empezó a hablar de un segundo tipo o clase de control de convencionalidad, el interno o difuso.

En términos generales, el control de convencionalidad se define como un:

"[M]ecanismo de protección procesal que ejerce la Corte Interamericana de Derechos Humanos, en el evento de que el derecho interno (Constitución, ley, actos administrativos, jurisprudencia, prácticas administrativas o judiciales, etc.), es incompatible con la Convención Americana sobre Derechos Humanos u otros tratados -aplicables-, con el objeto de aplicar la Convención u otro tratado, mediante un examen de confrontación normativo (derecho interno con el tratado)" 21 .

Así también, la dimensión concentrada del control de convencionalidad es entendida por el profesor Nogueira Alcalá como un mecanismo utilizado por la Corte IDH, tanto en sede consultiva como contenciosa para determinar la compatibilidad o incompatibilidad del Derecho interno o actos estatales con la Convención Americana, materializado en una sentencia en la que además se determina el alcance y sentido de las disposiciones convencionales $^{22}$; en esta medida: "el control de convencionalidad en sede internacional de la

16 SAGÜÉS (2010) p. 118.

17 Una posición contraria a la Corte Interamericana puede ser vista en: Vítolo (2013) y Malarino (2010).

18 Aguado Alfaro y otros vs. Perú (2006).

19 IbÁÑez Rivas (2015) pp. 104-105.

20 García Ramírez (2011) pp. 123-159.

21 Rey Cantor (2008) p. 46.

22 Nogueira Alcalá (2012) p. 1168. 
CIDH implica una subordinación de todo el ordenamiento jurídico al respeto y garantía de los derechos humanos asegurados convencionalmente"23.

Por su parte, el control de convencionalidad en sede nacional o en su dimensión difusa, hace referencia a aquél que se realiza en las jurisdicciones internas de los Estados cuyas autoridades deben confrontar las normas nacionales con las disposiciones de la Convención Americana a la luz de las interpretaciones hechas por la Corte Interamericana, a lo que terminarán sumándose otros instrumentos internacionales ratificados por el Estado, según la tesis más reciente de la Corte IDH.

En palabras de Ferrer Mac-Gregor, el control de convencionalidad difuso consiste en:

"[E]l examen de compatibilidad que siempre debe realizarse entre los actos y normas nacionales, y la Convención Americana sobre Derechos Humanos (CADH), sus Protocolos adicionales y la jurisprudencia de la Corte Interamericana de Derechos Humanos (Corte IDH), único órgano jurisdiccional del Sistema Interamericano de Protección los Derechos Humanos, que interpreta de manera "última" y "definitiva" el Pacto de San José"24.

Respecto de qué autoridades deben realizar el control de convencionalidad, la Corte Interamericana ha utilizado diferentes términos o tesis a lo largo de su jurisprudencia, pero ha sido claro el papel protagónico que están llamados a cumplir los jueces, quienes deben verificar, en los asuntos de su competencia, que las normas internas no vulneren el bloque de convencionalidad ${ }^{25}$. En este orden de ideas, los jueces principalmente, pero también las demás autoridades estatales (de acuerdo con la última posición de la Corte IDH) fungen como jueces y autoridades interamericanos.

Lo que a continuación se va a analizar es cómo uno de los altos tribunales colombianos, el Consejo de Estado, se ha apropiado de su rol como juez de convencionalidad y ha utilizado esta herramienta jurídica a la hora de proferir sus decisiones especialmente en casos en donde ciudadanos buscaban que se declarara responsable internacionalmente al Estado por daños antijurídicos causados. En concreto, lo que pasará a exponerse y a analizarse es la justificación que el Consejo de Estado ha encontrado para aplicar el control de convencionalidad en sus decisiones en las que se demanda la responsabilidad del Estado colombiano.

\section{EL CONTROL DE CONVENCIONALIDAD INTERNO EN LA JURISPRUDENCIA DEL CONSEJO DE ESTADO COLOMBIANO}

El Consejo de Estado colombiano ha acatado el control de convencionalidad interno, control que ha visionado como un aliado teórico para resolver los casos prácticos que se le presentan y como una herramienta jurídica para proteger los bienes jurídicos a su cargo. De allí que en los últimos años ${ }^{26}$ se encuentre un uso amplio y profuso del control de convencionalidad en su jurisprudencia.

\footnotetext{
23 Nogueira Alcalá (2012) p. 1168.

24 Ferrer Mac-Gregor (2011) pp. 531-532.

25 Noguiera Alcalá (2012) p. 1170.

26 Puntualmente la expedida durante los años 2011 a 2016.
} 
En efecto, el Consejo de Estado colombiano ha asumido su rol como juez de convencionalidad y ha acudido a la Convención Americana y a la jurisprudencia de la Corte $\mathrm{IDH}$, en casos en los que estaba de por medio graves violaciones a derechos humanos ${ }^{27}$, afectaciones a los derechos de $\operatorname{los}_{n} \operatorname{niños}^{28}$ y mujeres $^{29}$, la reparación integral ${ }^{30}$, el derecho a la salud ${ }^{31}$, la libertad de expresión ${ }^{32}$, el debido proceso $^{33}$ y los derechos al buen nombre y a la honra ${ }^{34}$, entre otros.

No obstante, el propósito del presente trabajo no es adentrarse en un análisis casuístico de la aplicación del control de convencionalidad por parte del Consejo de Estado sino comprender la justificación ofrecida por este alto tribunal para actuar como juez de convencionalidad. Esto permite ver qué tanta influencia ha tenido la argumentación de la Corte Interamericana para convencer a las autoridades judiciales nacionales del deber de realizar un control de convencionalidad y su importancia en la garantía de los derechos humanos.

La actividad del Consejo de Estado colombiano es de interés para la doctrina del hemisferio americano, puesto que, siendo juez constitucional residual, ha asumido un rol activo en la garantía de la convencionalidad de las actuaciones del Estado colombiano, resolviendo los casos que están dentro de su competencia judicial.

Pese a que, en un primer momento pudiera pensarse que a nivel nacional el primer tribunal llamado a aplicar con rigurosidad el control de convencionalidad es la Corte Constitucional, pues siempre se ha pretendido hacer un paralelo entre este control y el de constitucionalidad y además porque la Convención Americana de Derechos Humanos hace parte del bloque de constitucionalidad ${ }^{35}$. En Colombia la autoridad judicial que ha acogido con mayor ímpetu la tesis de la Corte Interamericana relativa a la existencia de un deber de realizar un control de convencionalidad interno ha sido el Consejo de Estado y no la Corte Constitucional que por el contrario se ha mostrado más cautelosa en la adopción de esta controversial obligación internacional ${ }^{36}$.

27 Consejo de Estado. Sección Tercera. 28 de agosto de 2014. exp. 26251, 21 de noviembre de 2013. exp. 29764, 26 de febrero de 2015. Exp. 28666 y 29 de enero de 2014. Exp. 33806.

28 Consejo de Estado. Sección Tercera. 28 de agosto de 2014. Exp. 26251.

29 Consejo de Estado. Sección Tercera. 12 de febrero de 2014. Exp. 26013.

30 Consejo de Estado. Sección Tercera. 29 de enero de 2014. Exp. 33806 y 20 de octubre de 2014. Exp. 31250.

31 Consejo de Estado. Sección Tercera. 12 de febrero de 2014. Exp. 40802.

32 Consejo de Estado. Sección Tercera. 12 de noviembre de 2014. Exp. 28505 y 24 de octubre de 2016. Exp. 53057.

33 Consejo de Estado. Sección Tercera. 25 de febrero de 2016. Exp. 34791; 7 de septiembre de 2015. Exp. 52892.

34 Consejo de Estado. Sección Tercera. 27 de febrero de 2013, Exp. 24734.

35 En el ordenamiento jurídico colombiano, el bloque de constitucionalidad ha sido desarrollado por la jurisprudencia de la Corte Constitucional, tomando como sustento normativo el artículo 93 de la Constitución Política de 1991. Dentro del profuso desarrollo jurisprudencial, la Corte Constitucional ha distinguido entre el bloque de constitucional lato sensu y stricto sensu.

36 Una posición clara de la Corte Constitucional sobre la recepción de jurisprudencia interamericana en aplicación del control de convencionalidad puede verse en la Sentencias C-500 de 2014. En esta decisión la Corte Constitucional sostuvo que para que la jurisprudencia interamericana tuviera la capacidad de cuestionar la cosa juzgada constitucional, es decir, que con fundamento en la jurisprudencia de la Corte IDH se examinará 
Así las cosas, resulta de interés conocer las razones que esgrime el Consejo de Estado para justificar la realización de un control de convencionalidad a la hora de determinar la responsabilidad del Estado colombiano en ejercicio de la acción de reparación directa.

Una primera hipótesis apuntaba a que el Consejo de Estado colombiano adoptaba completamente la justificación de la Corte Interamericana, pero por otra parte existía la posibilidad de que se dieran razones adicionales en esa misma línea o en una diferente. De allí que los argumentos que se encontraron en las sentencias del Consejo de Estado se expondrán en dos grandes grupos: (i) aquellos que coinciden plenamente con la jurisprudencia de la Corte IDH y (ii) aquellos que son adicionales o que surgen a partir de un contexto específico al que se enfrentó el tribunal contencioso administrativo colombiano.

La realización en particular del control de convencionalidad por parte del Consejo de Estado y, en general, la aplicación de instrumentos y decisiones interamericanas ha tenido un alto impacto en el ordenamiento jurídico, social y político colombiano. Aunque se podrían ofrecer varios ejemplos, el que lo ilustra de mejor manera, la reciente decisión de la Sala Plena del Consejo de Estado en la que resolvió la cuestión de si la Procuraduría General de la Nación es competente para imponer la sanción de inhabilidad y destitución a un funcionario público elegido por voto popular de conformidad con el ordenamiento jurídico interno y el Sistema Interamericano de Derechos Humanos.

Examinado el caso en concreto se consideró que el artículo 44.1 de la Ley 734 de 2002 (Código Único Disciplinario) contraviene el artículo 23.2 de la Convención y que consecuentemente, "la Procuraduría General de la Nación carecía de competencia para imponer una sanción que restringiera, casi que a perpetuidad, los derechos políticos de una persona, para ser elegida en cargos de elección popular, como también para separarlo del cargo de Alcalde Mayor de Bogotá para el que fue elegido mediante sufragio universal”.

Los argumentos que sirven de fundamento al Consejo de Estado para sustentar la carencia de competencia de la Procuraduría ${ }^{37}$ son de diferente naturaleza. En primer lugar, el acto administrativo mediante el cual el entonces alcalde de Bogotá fue destituido e inhabilitado para desempeñar cargos públicos durante 15 años, no fue motivado por hechos constitutivos de corrupción, lo que originó la violación al artículo 23.2 convencional, que dispone que solo un juez penal mediante sentencia condenatoria puede restringir los derechos políticos de una persona.

En segundo lugar, la destitución de un funcionario elegido por voto popular viola los derechos políticos del pueblo, facultado para elegir a sus gobernantes; de tal forma que mantener vigente una sanción que restringe los derechos políticos del funcionario elegido,

nuevamente un caso decidido por la Corte Constitucional, debían reunirse ciertas circunstancias, a saber: "(i) el parámetro de control del asunto previamente examinado haya sido una norma integrada al bloque de constitucionalidad en sentido estricto; (ii) los pronunciamientos de la Corte Interamericana de Derechos Humanos hayan variado radicalmente y de forma clara el sentido de tal norma; (iii) la nueva interpretación resulte compatible con la Constitución Política; (iv) ofrezca un mayor grado de protección a los derechos, que el otorgado por la Constitución; (v) se integre a la ratio decidendi de las decisiones de la Corte Interamericana de Derechos Humanos; y (vi) sea uniforme y reiterada. En estos casos, destaca la Corte, el demandante tendrá la obligación de demostrar con absoluta precisión cada uno de los requisitos antes referidos".

37 Convención Interamericana contra la Corrupción suscrita 29 de marzo de 1996. 
implica "hacer nugatorios los derechos políticos de sus electores" ${ }^{38}$. Considera también que al funcionario público destituido se le viola el principio de favorabilidad o pro homine, porque según la interpretación que hace del artículo 23.2 convencional, estos derechos solo pueden ser restringidos por un funcionario judicial, mediante sentencia ${ }^{39}$.

Como puede apreciarse el Consejo de Estado traza un criterio jurisprudencial de importante impacto, consistente en establecer que, a la luz de la Convención Americana, la Procuraduría General de la Nación no tiene competencia para destituir e inhabilitar funcionarios públicos elegidos por voto popular, en la medida que esta facultad de manera exclusiva corresponde al juez competente, como resultado de un proceso judicial.

\subsection{Justificación esgrimida POR el Consejo de Estado QUe es Coincidente CON LA JURISPRUDENCIA INTERAMERICANA}

\subsubsection{Todas las autoridades nacionales, especialmente los jueces, deben hacer un control de convencionalidad interno o difuso}

El Consejo de Estado entiende, al igual que lo hace la Corte IDH, que todos los jueces nacionales están obligados a hacer un control de convencionalidad interno, siguiendo así lo señalado en el caso Almonacid Arellano v. Chile (2006) por el tribunal interamericano ${ }^{40}$.

Al mismo tiempo considera que, aunque el papel del juez en la salvaguarda de los derechos humanos es especialmente relevante y por ello es el primer llamado a aplicar el control de convencionalidad, todas las autoridades estatales deben respetar la Convención Americana e incluso hacer prevalecer sus disposiciones por sobre las del ordenamiento jurídico nacional ${ }^{41}$ :

"En suma, dada la imperiosa observancia de la convencionalidad basada en los Derechos reconocidos en la Convención Americana de Derechos Humanos y la jurisprudencia decantada por la Corte Interamericana, como criterio interpretativo vinculante, es que se encuentra suficiente fundamento para estructurar el deber jurídico oficioso de las autoridades estatales -y en particular de los jueces- de aplicar la excepción de in-convencionalidad para favorecer las prescripciones normativas que emanan de la Convención por sobre los actos jurídicos del derecho interno" ${ }^{42}$.

En esa misma línea, el Consejo de Estado considera que en los casos de violaciones de derechos humanos el juez nacional es también un juez interamericano y debe actuar como tal lo que, traducido a sus competencias, implica ejercer un control de convencio-

\footnotetext{
38 Consejo de Estado. Sección Tercera. 15 de noviembre de 2017. Exp. 11312014.

39 Consejo de Estado. Sección Tercera. 15 de noviembre de 2017. Exp. 11312014.

${ }^{40}$ Consejo de Estado. Sección Tercera. 28 de agosto de 2014. Exp. 26251, 26 de febrero de 2015. Exp. 28666 y 12 de febrero de 2014. Exp. 26013.

${ }^{41}$ Consejo de Estado. Sección Tercera. 12 de noviembre de 2014. Exp. 28505, 3 de diciembre de 2014. Exp. 35413; 24 de octubre de 2016. Exp. 53057, 7 de septiembre de 2015. Exp. 52892 y 25 de febrero de 2016. Exp. 34791.

${ }^{42}$ Consejo de Estado. Sección Tercera. 25 de febrero de 2016. Exp. 34791.
} 
nalidad a la conducta del Estado -tanto por acción como por omisión-para determinar si quebrantó normas internacionales de derechos humanos ${ }^{43}$.

\subsubsection{El estado no puede obstaculizar el cumplimiento de obligaciones internacionales justificado en disposiciones de derecho nacional y debe respetar la finalidad de los tratados internacionales suscritos}

Por otra parte, pero siguiendo también la línea argumentativa de la Corte Interamericana, el Consejo de Estado ha entendido que la posibilidad de efectuar una excepción de inconvencionalidad -en ejercicio del control de convencionalidad- encuentra su justificación en la imposibilidad del Estado para sustentar el incumplimiento de acuerdos internacionales en sus propias normas jurídicas nacionales aunado a la pretensión de garantizar la efectiva protección de los derechos humanos y el funcionamiento de la democracia ${ }^{44}$.

En palabras del Consejo de Estado, su rol como juez de convencionalidad:

"[S]e fundamenta no solo en la prohibición que tiene todo Estado parte de un tratado de no oponer su derecho interno para incumplir los acuerdos internacionales, ${ }^{45}$ sino también en la pretensión de justicia que intrínsecamente encierran las disposiciones convencionales, comoquiera que el telos de ésta y de su interprete último es el de privilegiar la vigencia de los Derechos Humanos y del principio democrático en cada uno de los países firmantes de la Convención" 46 .

Aunque en la jurisprudencia analizada el tribunal nacional no hace referencia directa a las decisiones de la Corte IDH para dar la justificación que acaba de exponerse, este argumento es muy similar al encontrado en la jurisprudencia interamericana, según la cual el deber de realizar un control de convencionalidad es la materialización del principio del efecto útil que cobija a la Convención Americana. Según este principio de derecho internacional, los Estados deben cumplir sus compromisos de buena fe y asegurando la eficacia de sus disposiciones sin que les esté permitido utilizar su ordenamiento interno para obstaculizar los fines de la Convención ${ }^{47}$.

\subsubsection{Principio de complementariedad}

Comenzando el año $2016^{48}$, el Consejo de Estado, conoció de una acción de reparación directa en la que se evaluaba la responsabilidad estatal por la toma de la base militar “Las Delicias" en 1998 por parte del grupo insurgente de las FARC-EP. Dentro de este pro-

\footnotetext{
${ }^{43}$ Cfr. Consejo de Estado. Sección Tercera. 21 de noviembre de 2013. Exp. 29764.

44 Consejo de Estado. Sección Tercera. 3 de diciembre de 2014. Exp. 35413, 25 de febrero de 2016. Exp. 34791, 24 de octubre de 2016. Exp. 53057 y 7 de septiembre de 2015. Exp. 52892.

45 Se trata del artículo 27 de la Convención de Viena de 1969 sobre el derecho de los tratados, que establece: "El derecho interno y la observancia de los tratados. Una parte no podrá invocar las disposiciones de su derecho interno como justificación del incumplimiento de un tratado. Esta norma se entenderá sin perjuicio de lo dispuesto en el artículo 46".

46 Consejo de Estado. Sección Tercera. 3 de diciembre de 2014. Exp. 35413.

47 Aguado Alfaro y otro vs Perú (2006).

48 Consejo de Estado. Sección Tercera. 25 de febrero de 2016. Exp. 34791.
} 
ceso, los accionantes eran familiares de uno de los soldados regulares que fue secuestrado por el grupo guerrillero durante la cruenta toma a la base militar.

Sobre los hechos, el alto tribunal contencioso administrativo sostuvo que por "las condiciones en las que este tipo de eventos se viene produciendo en el Estado colombiano en el marco del conflicto armado interno, su encuadramiento se enmarca como un caso constitutivo de una grave vulneración de los derechos humanos, violación del derecho internacional humanitario, y configuración como acto de lesa humanidad”49.

Es en este contexto en el que el Consejo de Estado justifica la aplicación del control oficioso de convencionalidad. Para ello reitera los argumentos que se acaban de exponer pero al mismo tiempo adiciona el principio de complementariedad entre el ordenamiento nacional y el Sistema Interamericano de Derechos Humanos haciendo referencia la sentencia de la Corte Interamericana en el caso García Ibarra v. Ecuador, en virtud del cual "en la jurisprudencia de la Corte [IDH], se ha desarrollado la concepción de que todas las autoridades y órganos de un Estado Parte en la Convención tiene la obligación de ejercer un 'control de convencionalidad'. De este modo, solamente si un caso no se ha solucionado a nivel interno, como correspondería primariamente hacerlo a cualquier Estado Parte en la Convención en ejercicio efectivo del control de convencionalidad, entonces el caso podría llegar ante el Sistema" ${ }^{50}$.

Siguiendo esta misma línea argumentativa, el Consejo de Estado considera que todo juez nacional no solo "debe respetar su propio ordenamiento jurídico sino que además debe realizar una 'interpretación convencional para determinar si aquellas normas son 'compatibles' con los mínimos previstos en la Convención Americana de Derechos Humanos y en los demás tratados y preceptos del derecho internacional de los derechos humanos y del derecho internacional humanitario [sin que la convencionalidad sea absoluta, ya que puede limitarse precisamente a la tutela interna de los derechos fundamentales, esenciales y a los principios democráticos básicos, tal como lo ha sostenido el Tribunal Constitucional Alemán en las sentencia Solange I, Solange II, Maastricht, Lisboa, entre otras]"51.

El último aparte en negrillas (subrayado en el original de la sentencia), hace énfasis en que la convencionalidad no puede ser absoluta, o en otras palabras, que no necesariamente debe prevalecer la interpretación convencional sobre las normas internas en todos los casos a los que se enfrenten las autoridades judiciales, sino que ello está limitado a la protección interna de los derechos fundamentales y a los principios democráticos, conclusión a la que se llega con fundamento en jurisprudencia del Tribunal Constitucional de Alemania.

La idea de que la convencionalidad no es absoluta constituye un elemento novedoso dentro de la jurisprudencia del Consejo de Estado relacionada con la aplicación del control de convencionalidad, pues hasta el momento no había acotado de esta forma "la convencionalidad". Es decir, aunque toma como punto de partida que los jueces no solo están

\footnotetext{
${ }_{49}$ Consejo de Estado. Sección Tercera. 25 de febrero de 2016. Exp. 34791.

50 García IbarRa vs. ECUADOR (2015) citada por el Consejo de Estado en la Sentencia del 25 de febrero de 2016. Exp. 34791.

51 GARCIA IBARRA VS. ECUADOR (2015) citada por el Consejo de Estado en la Sentencia del 25 de febrero de 2016. Exp. 34791.
} 
sometidos al derecho nacional sino también a la Convención Americana, y en este sentido coincide con la postura de la Corte IDH, precisa que ese deber de convencionalidad no se predica respecto de todos los temas o en todos los casos, sino únicamente en aquellos en los que se esté limitando la protección de los derechos humanos y del principio democrático. Pese a que la Corte IDH no ha hecho una precisión en este sentido y con tal claridad, es posible afirmar que está implícito en el mandato de la Corte IDH, el cual se circunscribe a la garantía de los derechos, libertades y principios consagrados en la $\mathrm{CADH}$.

\subsubsection{Deberes generales del estado}

Por otra parte, el Consejo de Estado coincide con la Corte Interamericana en que la realización del control de convencionalidad tiene una estrecha relación con los deberes generales del Estado en materia de Derechos Humanos.

En efecto, a juicio de la Corte Interamericana, los deberes generales de los Estados contenidos en los artículos 1.1 y 2 de la Convención Americana, sirven para justificar la existencia del control de convencionalidad, especialmente éste último que establece la obligación de los Estados de adecuar su ordenamiento interno a los términos de la CADH, de tal forma que el control de convencionalidad interno aparece como una herramienta eficaz y eficiente para su cumplimiento ${ }^{52}$.

No obstante, la relación que el Consejo de Estado encuentra entre la realización del control de convencionalidad y los deberes generales estatales está dirigida a que, a partir de la Convención Americana, el juez puede determinar los deberes estatales en materia de protección de derechos humanos.

En caso concreto el Consejo de Estado se refiere a la obligación asumida por los Estados Partes de la Convención Americana (art. 1.1.) de respetar los derechos y libertades reconocidos en la Convención, sumada a la obligación de garantizar el libre y pleno ejercicio de los derechos reconocidos en la CADH a toda persona sujeta a su jurisdicción, mediante un aparato gubernamental, de instituciones y estructura del poder público que asegure jurídicamente el libre y pleno ejercicio de los derechos humanos a través de la prevención, investigación y sanción de las violaciones de derechos humanos, para lograr el restablecimiento del derecho conculcado y, en su caso, la reparación de los daños producidos ${ }^{53}$.

De igual forma, se menciona el deber estatal de "adoptar, con arreglo a sus procedimientos constitucionales internos, las medidas legislativas o de otro carácter que fueren necesarias para hacer efectivos y plenamente aplicables en el orden nacional los derechos y libertades reconocidos; en otras palabras, ajustar el derecho interno a esas disposiciones del ámbito internacional" 54 , de conformidad a lo previsto en el artículo 2 de la Convención Americana.

Así las cosas, la Convención Americana adquiere una especial importancia en los casos en los que se analiza la responsabilidad del Estado por violaciones a derechos humanos pues ella contiene los deberes generales en esa materia, de tal forma que es un referente que el

\footnotetext{
52 Cfr. (2015) p. 34. Ver al respecto: Caso AlmonaCid ArRellano vs. Chile (2006), Rosendo Cantú vs. México (2010), FERNÁNDEZ ORTEGA Y OtROS. VS. MÉXICO (2010).

53 Consejo de Estado. Sección Tercera. 24 de junio de 2014. Exp. 26029.

54 Consejo de Estado. Sección Tercera. 24 de junio de 2014. Exp. 26029.
} 
Consejo de Estado tiene en cuenta a la hora de fallar acciones de reparación directa en las que se busca la reparación de los daños causados a bienes jurídicos fundamentales, i.e. derechos humanos, lo que se traduce en la realización de un control de convencionalidad interno.

\subsection{JUSTIFICACIÓN ESGRIMIDA POR EL CONSEJO DE ESTADO ADICIONAL A LA OFRECIDA POR LA JURISPRUDENCIA INTERAMERICANA \\ Después de haber estudiado los argumentos que el Consejo de Estado ha expuesto} en su jurisprudencia para justificar su rol como juez de convencionalidad y la necesidad de realizar un control de convencionalidad coincidentes con la línea argumentativa defendida por la Corte Interamericana, corresponde ahora explorar aquellas razones adicionales que también están presentes en las decisiones del alto tribunal colombiano.

Lo que se ha visto hasta el momento corresponde a argumentos sustentados en el Derecho Internacional Público y más concretamente en el Derecho Internacional de los Derechos Humanos, lo que a su vez explica la coincidencia con la jurisprudencia interamericana.

Sin embargo, como se anunció, en el estudio jurisprudencial realizado se evidenció que el Consejo de Estado también justifica la realización del control de convencionalidad en argumentos eminentemente constitucionales reforzados por la gravedad e importancia de las circunstancias fácticas del caso que debe resolver.

Este segundo grupo de argumentos tiene una especial importancia puesto que constituyen una justificación del control de convencionalidad interno desde el ordenamiento jurídico nacional. Es decir, el Consejo de Estado hizo un esfuerzo por verificar que la realización de este control -originado en un sistema regional de protección de derechos humanos- tuviera también asidero en la constitución y realidad colombiana.

Esfuerzo que debe ser altamente valorado si se tiene en cuenta que no hay un consenso sobre la existencia de un fundamento normativo convencional que expresamente establezca el deber de los Estados de realizar un control de convencionalidad interno respecto de sus normas nacionales y por parte de todas sus autoridades públicas, utilizando como parámetro de convencionalidad tanto el texto de la $\mathrm{CADH}$ como la jurisprudencia de la Corte IDH.

\subsubsection{Bloque de constitucionalidad}

En el orden de ideas que se acaba de plantear, el Consejo de Estado acude a los artículos 93 y 94 de la Constitución Política colombiana, considerados como el fundamento normativo de la figura del bloque de constitucionalidad ${ }^{55}$.

El alto tribunal colombiano considera que la realización del control de convencionalidad de las normas internas en el que el juez contencioso debe hacer un juicio de compara-

\footnotetext{
55 El bloque de constitucionalidad puede entenderse como una herramienta jurídica que permite la integración de instrumentos de diferente naturaleza jurídica a la constitución material. Inicialmente, permitía a la Corte Constitucional la utilización de normas internacionales para el análisis de constitucionalidad de las leyes, no obstante, mediante un desarrollo jurisprudencial profuso (que inició en 1995) su alcance se fue ampliando y adquirió un relevante valor hermenéutico.
} 
ción de estas con los instrumentos jurídicos internacionales ${ }^{56}$, está justificado en el bloque ampliado de constitucionalidad. Esta idea, sumada a una interpretación sistemática de los artículos 1, 2, 4, 13 a 29, 90, 93 y 94 de la Carta Política, ha sido usada para justificar que actualmente en el derecho administrativo el énfasis está en los derechos de la víctima y no la actividad del Estado como tradicionalmente se ha entendido ${ }^{57}$.

Se destaca que se usa el término de bloque ampliado de constitucionalidad que no corresponde literalmente con las categorías desarrolladas por la jurisprudencia de la Corte Constitucional -stricto (estricto) y lato (amplio) sensu- que ha sido donde se ha desarrollado la doctrina del bloque de constitucionalidad con fundamento en los artículos 93 y 94 superiores. Sin embargo, consideramos que el Consejo de Estado se refiere al bloque de constitucionalidad lato sensu pues en él incluye instrumentos internacionales de diferente jerarquía y no lo restringe a tratados internacionales ratificados por Colombia que versen sobre derechos humanos que no pueden ser suspendidos en los estados de excepción ${ }^{58}$.

En este orden de ideas, el Consejo de Estado utiliza el bloque de constitucionalidad en sentido amplio para justificar el deber de realizar un control de convencionalidad interno.

Pese a que no se da una explicación detallada en ese sentido, pudiera pensarse que ello se fundamenta en que el referido control se origina en la jurisprudencia de la Corte IDH, y tales decisiones no hacen parte del bloque de constitucionalidad en estricto sentido, sino únicamente sentido lato. A este planteamiento, podría objetarse diciendo que el Consejo de Estado entiende que el deber de efectuar un control de convencionalidad interno se deriva del texto de la CADH y de los principios del Derecho Internacional, de tal forma que la jurisprudencia interamericana no crea el deber, sino que, a lo sumo lo cristaliza.

No obstante, el punto que se acaba de exponer merece un estudio ulterior que desborda la finalidad de esta investigación, por lo que se anima a otros autores a hacer un estudio en ese sentido.

Lo cierto es que, para el Consejo de Estado hay una estrecha relación entre el bloque de constitucionalidad y el control de convencionalidad, de tal forma que con fundamento en la Constitución los jueces contencioso-administrativos están en la obligación de realizar el control de convencionalidad interno.

En efecto, considera que el inciso primero del artículo 93 constitucional, hace una integración normativa -del Derecho Internacional en el nacional- que permite la aplicabilidad directa de las disposiciones sobre derechos humanos que hayan sido ratificadas por Colom-

\footnotetext{
56 Aunque el Consejo de Estado no da una conceptualización de este término, sí da como ejemplos los tratados, los convenios y los acuerdos de protección de derechos humanos y del Derecho Internacional Humanitario, ya sea que estén incorporados al ordenamiento nacional o que se trate de normas de ius cogens.

57 Consejo de Estado. Sección Tercera. 3 de diciembre de 2014. Exp. 35413, reiterada en la Sentencia del 25 de febrero de 2016 Exps. 37226 y 34791.

$58 \mathrm{Al}$ respecto pueden verse las sentencias Consejo de Estado. Sección Tercera. 26 de febrero de 2015. Exp. 28666, 25 de febrero de 2016. Exp. 37226, 3 de diciembre de 2014. Exp. 35413, 27 de febrero de 2013. Exp. 24734, 12 de febrero de 2014 Exp. 26013; 25 de febrero de 2016 Exp. 3479, 29 de febrero de 2016. Exp. 35298 y 25 de febrero de 2016 Exp. 36343.
} 
bia, de tal forma que mediante el control de convencionalidad se verifique la efectividad de los derechos y garantías contenidas en esos instrumentos, que califica de supranacionales ${ }^{59}$.

Así también, considera que a través del bloque de constitucionalidad se introducen al ordenamiento constitucional no solo la normativa internacional sobre derechos humanos sino también la interpretación que de ella se ha hecho por las cortes internacionales competentes, de donde se deriva la obligación de efectuar un control de convencionalidad a la conducta del Estado ${ }^{60}$.

El Consejo de Estado, además de las normas convencionales de Derechos Humanos y del Derecho Internacional Humanitario, ha entendido que las normas consuetudinarias del DIH también hacen parte del bloque de constitucionalidad ${ }^{61}$. Esta visión aplicada por el Consejo de Estado va en consonancia con la Corte Constitucional quien ha considerado que las normas consuetudinarias del DIH hacen parte del bloque de constitucionalidad en sentido estricto, de allí que las haya usado como parámetro de constitucionalidad de leyes nacionales justificando por ejemplo la inexequibilidad de la expresión "debidamente señalados con los signos convencionales” de los artículos 156 y 157 de la Ley 599 de $2000^{62}$.

En este orden de ideas, se tiene que el Consejo de Estado ha encontrado en la figura del bloque de constitucionalidad un sustento jurídico desde el orden nacional para justificar la aplicación de normas internaciones y la necesidad de la realización de un control de convencionalidad que, como puede advertirse, no se limita a la aplicación de normas de la Convención Interamericana, sino que, además, abarca disposiciones internacionales de diferente naturaleza y origen.

Por otra parte, el Consejo de Estado entiende que "la jurisdicción interna, en ejercicio de la administración de justicia, está llamada a actuar como juez interamericano a nivel nacional en los casos de graves violaciones a derechos humanos"63 y que, la necesidad de ejercer el control de convencionalidad se deriva de un imperativo internacional proveniente de la Convención Americana, pero al mismo tiempo destaca que esta convención es "fuente de derecho a nivel nacional, en razón del artículo 230 de la Constitución Política, lo que es posible, gracias a la articulación del sistema interamericano al ordenamiento jurídico, a través artículo 93 de la misma Carta" ${ }^{64}$; lo que le permite al juez administrativo declarar la responsabilidad extracontractual del Estado por los daños antijurídicos usando como fundamento normativo último la Convención Americana de Derechos Humanos ${ }^{65}$ y de igual forma, vía excepción de inconstitucionalidad abstenerse de aplicar un acto administrativo por considerarlo contrario no solo a la Constitución sino también a la Convención Americana (artículos 1.1 y 2$)^{66}$.

\footnotetext{
59 Consejo de Estado. Sección Tercera. 21 de noviembre de 2013. Exp. 29764.

60 Consejo de Estado. Sección Tercera. 21 de noviembre de 2013. Exp. 29764.

61 Consejo de Estado. Sección Tercera. 26 de febrero de 2015. Exp. 28666

62 Corte Constitucional, Sentencia C-291 de 2007.

63 Consejo de Estado. Sección Tercera. 21 de noviembre de 2013. Exp. 29764.

64 Consejo de Estado. Sección Tercera. 21 de noviembre de 2013. Exp. $29764 .$.

${ }^{65}$ Consejo de Estado. Sección Tercera. 21 de noviembre de 2013. Exp. 29764.

66 Así ocurrió en el Auto de la Sala Plena de la Sección Tercera del Consejo de Estado del 22 de octubre de 2015. Exp. 42423, en el que se inaplicó el artículo 7º del Decreto 1303 de 2014 en lo referente a la Fiscalía Ge-
} 


\subsubsection{Prevalencia del derecho sustancial sobre lo formal}

En la construcción de este argumento, el Consejo de Estado acudió nuevamente a disposiciones constitucionales para justificar la realización del control de convencionalidad y su rol como juez de convencionalidad. Puntualmente, acudió al principio constitucional de la prevalencia del derecho sustancial sobre los aspectos formales (artículo 228 C.P.) para justificar desde el derecho interno, la aplicación preferente de normas convencionales.

En efecto, el Consejo de Estado considera que en los casos en los que se debe valorarse "la ocurrencia de vulneraciones al Derecho Internacional Humanitario y al Derecho Internacional de los Derechos Humanos, procede ejercer un control de convencionalidad que permita la prevalencia de lo sustancial sobre los aspectos adjetivos, procesales, ya que de no hacerlo se estaría vulnerando la Convención Americana de Derechos Humanos al no garantizarse el acceso a la justicia en todo su contenido como derecho humano reconocido constitucional y supraconstitucionalmente" ${ }^{\text {"67 }}$.

Para reforzar este punto, el alto tribunal colombiano, acude a la sentencia de la Corte Interamericana en el caso Manuel Cepeda vs. Colombia, en la que se le llamó la atención al Consejo de Estado porque en uno de los casos no valoró "los resultados parciales de las investigaciones penales y disciplinarias en las que constaba la responsabilidad de los dos sargentos del Ejército Nacional, por considerar que la documentación fue remetida en copia simple" ${ }^{68}$. Todo esto, como lo señala el Consejo de Estado, está enmarcado en un proceso de constitucionalización de la responsabilidad del Estado que ha llevado a examinar cada uno de los elementos que le sirven de fundamento a la luz del Derecho Constitucional que a su vez ha venido aumentando su interacción con el Derecho Internacional y en particular con el DIH y el DIHD ${ }^{69}$.

En desarrollo del anterior postulado, el Consejo de Estado ha flexibilizado el rigor aplicado a la hora de tener como válido material probatorio dentro de procesos en los que se estudia la posible violación de derechos humanos ${ }^{70}$, utilizando como fundamento normativo los artículos 1, 2, 8.1 y 25 de la Convención Americana a su vez sustentados en los artículos 29 y 228 de la Constitución Política.

Bajo esta misma argumentación, el Consejo de Estado ha flexibilizado las reglas procesales para así poder reconocer como accionante a un menor de edad al que se le habían negado sus pretensiones en primera instancia puesto que el Tribunal no encontró prueba de su parentesco con la víctima ${ }^{71}$. En esta oportunidad, el Consejo de Estado entendió que su

neral de la Nación como destinataria de los procesos judiciales y conciliaciones prejudiciales en los que estuviere involucrado el DAS.

67 Consejo de Estado. Sección Tercera. 25 de febrero de 2016. Exp. 34791.

68 Manuel Cepeda vs. Colombia (2010). También pueden verse: Consejo de Estado. Sección Tercera. s28 de agosto del 2013. Exp. 25022 y 28 de agosto de 2014. Exp. 32988.

${ }^{69}$ Manuel Cepeda vs. Colombia (2010). También pueden verse: Consejo de Estado. Sección Tercera. s28 de agosto del 2013. Exp. 25022 y 28 de agosto de 2014. Exp. 32988.

70 Por ejemplo, puede verse Consejo de Estado, Sentencia del 7 de septiembre de 2015, Consejero Ponente: Jaime Orlando Santofimio Gamboa, Exp. 52892.

71 En este caso el apoderado de los demandantes sostuvo que dicha prueba fue debidamente anexada y relacionada en la demanda y que su falta en el expediente es imputable a los funcionarios encargados de la manipulación de este en sede de primera instancia; sin embargo, para efectos de sanear la presunta irregularidad, el 
rol como juez de convencionalidad le imponía el deber de flexibilizar las normas procesales a fin de garantizar el interés superior del niño y la aplicación del principio de la prevalencia del derecho sustancial.

En este orden de ideas, se tiene que el Consejo de Estado ha acudido al principio de la prevalencia del derecho sustancial aludiendo como fundamento normativo tanto normas de derecho constitucional como internacional, en un doble sentido: (i) por un lado para justificar la prevalencia de normas internacionales - como lo es una regla de la Corte Interamericana en una sentencia contra Colombia-y, (ii) por otro justificar la flexibilización de normas procesales internas en su rol de juez de convencionalidad.

Conviene poner de manifiesto que, con esta argumentación, el Consejo de Estado, dejó en evidencia, que las autoridades judiciales colombianas cuentan con fundamento constitucional para flexibilizar las reglas procesales cuando con su aplicación excesivamente rigurosa se esté poniendo en riesgo la garantía de un derecho humano.

\subsubsection{Justificación fáctica}

En una línea argumentativa distinta a la que se ha expuesto hasta el momento, el Consejo de Estado justifica la realización del control de convencionalidad no en cuestiones dogmáticas o teóricas, sino en la gravedad y carácter especial del caso que debe resolver.

Concretamente se pudo evidenciar que en casos en los que se discute la realización de delitos de lesa humanidad ${ }^{72}$, graves violaciones a los derechos humanos ${ }^{73}$, protección a la población civil durante el conflicto armado $^{74}$ y la violación de los derechos de los niños ${ }^{75}$, el Consejo de Estado entiende que es necesario aplicar el bloque de convencionalidad para determinar la responsabilidad estatal. En este tipo de circunstancias el Consejo de Estado hace un estudio pormenorizado de los hechos y es a partir de ellos que entra a justificar la necesidad de realizar el referido control.

De allí que, una vez se determina que se trata de una controversia en la que está de por medio la realización de un acto de lesa humanidad que lesiona gravemente los derechos humanos, surge para el juez nacional el deber de efectuar un control de convencionalidad y así, en tanto juez de convencionalidad, se deriva la competencia para pronunciarse oficiosamente "sobre el contexto amplio que involucra esta situación, lo que implica la declaratoria de responsabilidad del Estado respecto de aquellos daños antijurídicos que le sean atribuibles, siempre que guarden relación o vínculo con este contexto" ${ }^{\prime 7}$.

Obrando como juez de convencionalidad, el juez nacional, al enfrentarse a un caso de tal magnitud, debe considerar a la sociedad como un todo y no solo fijarse en los sujetos

registro fue aportado junto al memorial presentado al Consejo de Estado. Sección Tercera. 29 de febrero de 2016. Exp. 35298

72 Consejo de Estado. Sección Tercera. 3 de diciembre de 2014. Exp. 35413.

73 Consejo de Estado. Sección Tercera. 21 de noviembre de 2013. Exp. 29764 y 26 de febrero de 2015 Exp. 28666.

74 Consejo de Estado. Sección Tercera. 12 de febrero de 2014. Exp. 26013.

75 Consejo de Estado. Sección Tercera. 28 de agosto de 2014. Exp. 26251. Sobre este tema también puede verse Corte Constitucional. Sentencia C-578 de 1995.

76 Consejo de Estado. Sección Tercera. 3 de diciembre de 2014. Exp. 35413. 
individualmente considerados que de forma concreta vieron vulnerados sus derechos por la acción u la omisión del Estado. Es con fundamento en ello, el Consejo de Estado dicta medidas generales no pecuniarias que están dirigidas a la sociedad y a la humanidad, sin que ello implique el reconocimiento de indemnizaciones particulares respecto de quienes no han promovido la pretensión contenciosa de reparación directa, por tratarse de intereses privados de cada víctima ${ }^{77}$.

Similar argumentación se dio cuando se debió resolver un caso en el que se discutía la violación de derechos de niños, en donde el Consejo de Estado señaló que son sujetos de una especial y prevalente protección tanto en el ámbito nacional como en el internacional. De allí que entienda que:

"La decisión del juez administrativo estará sustentada en la observancia de los instrumentos jurídicos internacionales, bien sea que se encuentren incorporados mediante una ley al ordenamiento nacional, o que su aplicación proceda con efecto directo atendiendo a su carácter de 'ius cogens', de manera que se consolide el principio de legalidad ampliado, no un simple principio de legalidad sujeto al bloque de constitucionalidad, sino que se invoca su ampliación con base en el bloque de convencionalidad, a cuyos estándares debe obedecer la actuación u operación administrativa en el Estado Social y Democrático de Derecho, mucho más cuando se trata de sujetos de especial protección como sucede en el caso que en esta oportunidad ocupa a la Sala"78.

De igual forma, el alto tribunal ha reconocido la especial importancia que tienen los casos en los que se discute la efectiva protección de la población civil dentro del conflicto armado interno, al señalar que se trata de un asunto que "no está reducido a los contornos de nuestra Carta Política, sino que se extiende a las cláusulas que en el derecho internacional público se consagran tanto en el ámbito internacional humanitario, como en el de la protección de los derechos humanos"79. El Consejo de Estado entiende que la protección de la población civil está prevista en la Constitución Política (artículos 1, 2, 93 y 94) "así como en los instrumentos jurídicos internacionales que en consideración del bloque ampliado de constitucionalidad, a su ratificación y al control de convencionalidad debe cumplir el juez contencioso administrativo, tanto en materia de derechos humanos, como de derecho internacional humanitario" ${ }^{\circ 0}$.

Así las cosas, se evidenció que en algunas ocasiones el Consejo de Estado justifica la realización del control de convencionalidad mediante la aplicación de la Convención Americana ${ }^{81}$ y su consecuente rol de juez de convencionalidad, en los hechos mismos que dan

\footnotetext{
77 Consejo de Estado. Sección Tercera. 3 de diciembre de 2014. Exp. 35413.

78 Consejo de Estado. Sección Tercera. 28 de agosto de 2014. Exp. 26251.

79 Consejo de Estado. Sección Tercera. 12 de febrero de 2014. Exp. 26013

80 Consejo de Estado. Sección Tercera. 12 de febrero de 2014. Exp. 26013.

81 Como pudo observarse, el Consejo de Estado no limita el control de convencionalidad a la aplicación de la Convención Americana y jurisprudencia interamericana, sino que entiende que también deben aplicarse otros instrumentos del Derecho Internacional de Derechos Humanos e incluso del Derecho Internacional Humanitario. Al respecto pueden verse Consejo de Estado. Sección Tercera. 12 de febrero de 2014. Exp. 26013 y 26 de febrero de 2015. Exp. 28666.
} 
origen a su decisión, ya sea por la calidad de los sujetos involucrados o por la gravedad de la violación de derechos humanos.

\section{CONCLUSIONES}

1. El Consejo de Estado colombiano ha asumido un rol activo como juez de convencionalidad, haciendo suyos los argumentos dados por la Corte Interamericana para justificar el deber estatal de realizar un control de convencionalidad interno pero, además, ofreciendo otros argumentos que tienen en consideración el ordenamiento jurídico colombiano. En particular, ha acudido a la figura del bloque de constitucionalidad con fundamento en el artículo 93 superior y en la jurisprudencia de la Corte Constitucional, así como al artículo 28 de la Constitución Política que consagra el principio de prevalencia del derecho sustancial sobre el derecho formal. Estos argumentos han sido esgrimidos por el Consejo de Estado tanto para justificar en general su papel como juez convencional, pero también, y quizás aún más importante, para justificar la utilización de la jurisprudencia interamericana en casos concretos.

2. Las características fácticas del caso concreto tienen especial relevancia para el Consejo de Estado a la hora de justificar la realización del control de convencionalidad. Esta línea argumentativa es importante si se tiene en cuenta que en el plano práctico para las autoridades judiciales resulta prácticamente imposible realizar un control de convencionalidad en cada uno de los casos que llegan a su conocimiento, de allí que es fundamental la identificación de elementos, fácticos o normativos, que permitan determinar si el caso en concreto debe ser resuelto con fundamento en la Convención Americana y en la jurisprudencia interamericana. Con esto no se quiere decir que solo en ciertos casos debe respetarse la $\mathrm{CADH}$, sino que, la aplicación del control de convencionalidad, con el rigor que impli$\mathrm{ca}$, no necesariamente debe tener lugar en todos los casos, sino que, las normas nacionales son suficientes para resolver la mayoría de los casos sin que ello implique una contradicción con la Convención Americana. Lo contrario, equivaldría a asumir que los ordenamientos jurídicos de los Estados son mayoritariamente inconvencionales.

3. Aunque la Corte Interamericana no ha utilizado los hechos del caso como criterios para determinar si era necesario o no que el Estado realizara un control de convencionalidad interno, aparece razonable inferir, tanto de su jurisprudencia como de su mandato, que únicamente pretende intervenir en asuntos en los que presuntamente hay una violación de derechos o libertades reconocidas por la Convención Americana. Este criterio puede servir de guía a las autoridades estatales a la hora de identificar los casos en los que se requiere verificar con detenimiento mediante el control de convencionalidad, la adecuación con la CADH.

4. Consideramos que el esfuerzo argumentativo del Consejo de Estado y, en general de las autoridades nacionales, para justificar la realización del control de convencionalidad tiene la capacidad de incidir en su afectividad y legitimidad, especialmente si se tiene en cuenta que la Convención Americana no establece expresamente el deber de realizar un control de convencionalidad que tenga como parámetro la jurisprudencia de la Corte IDH. De igual forma, consideramos valioso que la Corte Interamericana tenga en cuenta los ar- 
gumentos esgrimidos por los tribunales nacionales para que, dentro de un ámbito de diálogo judicial constructivo, se continúe fortaleciendo y moldeando la doctrina del control de convencionalidad.

\section{BIBLIOGRAFÍA CITADA}

Ferrer Mac-Gregor, Eduardo (2011): "Interpretación conforme y control difuso de convencionalidad. El nuevo paradigma del juez mexicano", Estudios Constitucionales, No 2: pp. 531-532.

García Ramírez, Sergio (2011): "El control judicial interno de convencionalidad", Revista del Instituto de Ciencias Jurídicas de Puebla, No. 28: pp. 123-159.

Londoño Lázaro, María Carmelina (2010): "El principio de legalidad y el control de convencionalidad de las leyes: confluencias y perspectivas desde el pensamiento de la Corte Interamericana de Derechos Humanos", Boletín Mexicano de Derecho Comparado, No 128: pp. 796-798.

Malarino, Ezequiel (2010): "Acerca de la pretendida obligatoriedad de la jurisprudencia de los órganos interamericanos de protección de derechos humanos para los tribunales judiciales nacionales", en ElSner, Gisela y Ambos, Kai (coord.), Sistema interamericano de protección de los derechos humanos y derecho penal internacional (Montevideo, Fundación Konrad Adenauer), pp. 425-446.

Nogueira Alcalá, Humberto (2012): "Desafíos del control de convencionalidad del corpus iuris interamericano para las jurisdicciones nacionales", Boletín Mexicano de Derecho Comparado, No 135: p. 1168.

Rey Cantor, Ernesto (2008): Control de Convencionalidad de las leyes y derechos humanos, (México, Editorial Porrúa, Instituto Mexicano de Derecho Procesal Constitucional).

SAGÜÉs, Néstor (2010): "Dificultades operativas del Control de Convencionalidad en el sistema interamericano" (La Ley, Tomo 2010-D).

SAGÜÉs, Néstor (2010): "Obligaciones internacionales y control de convencionalidad", Estudios Constitucionales No 1: pp. 117-136.

SuÁrez Osma, Ingrid (2015): "Control de Convencionalidad” en Ibañez (edit.), Control de Convencionalidad y Autoprecedente Interamericano, (Chía, Universidad de La Sabana) pp. 38-99.

Thury Cornejo, Valentín (2012): "La revisión del control de convencionalidad difuso y la identidad institucional de la Corte Interamericana”, en Jornadas argentino-chileno-peruano-uruguayas de Asociaciones de Derecho Constitucional. Montevideo Uruguay, 17 y 18 de 2011, sesión III. Disponible en: http://cedecu.edu.uy/uploads/media/mdCategory/bebf264aa42b3aa85e5afdcd20370855.pdf, fecha de consulta: 15 de mayo de 2013.

Vítolo, Alfredo (2013): “Una novedosa categoría jurídica: el 'querer ser' -acerca del pretendido carácter normativo erga omnes de la jurisprudencia de la Corte Interamericana de Derechos Humanos. Las dos caras del 'control de convencionalidad", Revista Pensamiento Constitucional, vol. 28, No. 18: pp. 357-380. 


\section{JURISPRUDENCIA CITADA}

JuRISPRUdENCIA CoRtes InTERnaCionales

ALmonacid ArRellano vs. Chile. Corte Interamericana de Derechos Humanos Sentencia de 26 de septiembre de 2006. Serie C No 154.

BOYCE VS. BARBADOS. Corte Interamericana de Derechos Humanos Sentencia de 20 de noviembre de 2007. Serie C No 204.

BAZÁN, Víctor (2012) en "Control de convencionalidad, aperturas dialógicas e influencias jurisdiccionales recíprocas", disponible en: http://www.pj.gov.py/ebook/libros_files/ Ponencia_V\%C3\%ADctor_Baz\%C3\%A1n.pdf Fecha de consulta: 27 de diciembre de 2014.

FERNÁNDEZ ORTEGA Y OTROS VS. MÉXICO. Corte Interamericana de Derechos Humanos Sentencia de 30 de agosto de 2010 Serie C No 215.

GELMAN VS. URUGUAY. Corte Interamericana de Derechos Humanos Sentencia de 24 de febrero de 2011. Serie C No 221.

MACK CHANG vs. GUATEMALA. Corte Interamericana de Derechos Humanos Sentencia del 25 de noviembre de 2003. serie C No 101.

Manuel Cepeda vs. Colombia Corte Interamericana de Derechos Humanos Sentencia del 26 de mayo de 2010. serie C No 213.

Masacres De Río Negro Vs. GUATEMALA. Corte Interamericana de Derechos Humanos Sentencia del 4 de septiembre de 2012. serie C No 250.

Masacre De Santo Domingo vs. Colombia. Corte Interamericana de Derechos Humanos Sentencia del 30 de noviembre de 2012. serie C No 259.

Olmedo Bustos vs. ChILE. Fondo, Reparaciones y Costas. Corte Interamericana de Derechos Humanos Sentencia de 5 de febrero de 2001. Serie C No 73.

Rosendo CANTÚ vs. MÉxICo. Corte Interamericana de Derechos Humanos, Sentencia de 31 de agosto de 2010 Serie C No 216.

RoCHAC HERNÁNDEZ Y OtRos VS. EL SALVADOR. Corte Interamericana de Derechos Humanos Sentencia del 14 de octubre de 2014. serie C No 285.

Trabajadores Cesados Del Congreso (Aguado Alfaro y Otros) vs. Perú. Corte Interamericana de Derechos Humanos Sentencia del 24 de noviembre de 2006, Serie C No 158.

VARGAS ARECo vs. PARAgUaY, Corte Interamericana de Derechos Humanos Sentencia del 26 de septiembre de 2006, Serie C No 155.

Convención Interamericana contra la Corrupción suscrita 29 de marzo de 1996.

\section{JuRISPRUDENCIA COLOMBiAna}

Consejo de Estado, Sentencia del 27 de febrero de 2013, Consejero Ponente: Jaime Orlando Santofimio, exp. 24734.

Consejo de Estado, Sentencia del 28 de agosto del 2013, Consejero Ponente: Ramiro de Jesús Pazos Guerrero, exp. 25022.

Consejo de Estado, Sentencia del 21 de noviembre de 2013, Consejero Ponente: Enrique Gil Botero, exp. 29764.

Consejo de Estado, Sentencia del 29 de enero de 2014, Consejero Ponente: Hernan Andrade Rincon, exp. 33806. 
Consejo de Estado, Sentencia del 12 de febrero de 2014, Consejero Ponente: Jaime Orlando Santofimio Botero, exp. 26013.

Consejo de Estado, Sentencia del 12 de febrero de 2014, Consejero Ponente: Jaime Orlando Santofimio Botero, exp. 40802

Consejo de Estado, Sentencia del 24 de junio de 2014, Consejero Ponente: Danilo Rojas Betancourth, exp. 26029.

Consejo de Estado, Sentencia del 28 de agosto de 2014, Consejero Ponente: Jaime Orlando Santofimio Botero, exp. 26251.

Consejo de Estado, Sentencia del 28 de agosto del 2014, Consejero Ponente: Ramiro de Jesús Pazos Guerrero, exp. 32988.

Consejo de Estado, Sentencia del 20 de octubre de 2014, Consejero Ponente: Jaime Orlando Santofimio Botero, exp. 31250.

Consejo de Estado, Sentencia del 12 de noviembre de 2014, Consejero Ponente: Jaime Orlando Santofimio Botero, exp. 28505.

Consejo de Estado, Sentencia del 3 de diciembre de 2014, Consejero Ponente: Jaime Orlando Santofimio Botero, exp. 35413.

Consejo de Estado, Sentencia del 26 de febrero de 2015, Consejero Ponente: Jaime Orlando Santofimio Botero, exp. 28666

Consejo de Estado, Sentencia del 7 de septiembre de 2015, Consejero Ponente: Jaime Orlando Santofimio Gamboa, exp. 52892.

Consejo de Estado, Sentencia del 22 de octubre de 2015, Consejero Ponente: Jaime Orlando Santofimio Gamboa, exp. 42423

Consejo de Estado, Sentencia del 25 de febrero de 2016, Consejero Ponente: Jaime Orlando Santofimio Botero, exp. 34791.

Consejo de Estado, Sentencia del 25 de febrero de 2016, Consejero Ponente: Jaime Orlando Santofimio Botero, exp. 36343.

Consejo de Estado, Sentencia del 25 de febrero de 2016, Consejero Ponente: Jaime Orlando Santofimio Botero, exp. 37226.

Consejo de Estado, Sentencia del 29 de febrero de 2016, Consejero Ponente: Jaime Orlando Santofimio Botero, exp. 35298.

Consejo de Estado, Sentencia del 24 de octubre de 2016, Consejero Ponente: Jaime Orlando Santofimio Botero, exp. 53057.

Consejo de Estado Sala Plena, Sentencia del 15 de noviembre de 2017, Consejero Ponente: Cesar Palomino Cortés, exp. 1131-2014.

Corte Constitucional, Sentencia del 19 de mayo de 1995, Magistrado Ponente: Eduardo Cifuentes Muñoz, Sentencia C-578.

Corte Constitucional, Sentencia del 25 de abril 2007, Magistrado Ponente: Manuel José Cepeda Espinosa, Sentencia C-291.

Corte Constitucional, Sentencia del 25 de mayo 2011, Magistrado Ponente: Humberto Antonio Sierra Porto, Sentencia C-442.

Corte Constitucional. Sentencia del 16 de julio de 2014. Magistrado Ponente: Mauricio González Cuervo, Sentencia C-500. 